\title{
The effect of letter frequency on anagram solution times
}

JERRY L. COHEN 1 , DEPARTMENT OF PSYCHOLOGY. THE PENNSYLVANIA STATE UNIVLRSITY. University Park, Pa. 16802

Letter frequenc'y was yaried by selecting words with either high or low individual letter frequency totals, while holding constant the average word transition probability and the average anagram transition probability rariables. Fifteen female Ss were tested on the anagram task. The results showed that for 2 min solution periods words of low letter frequency were solved significantly faster and more often than words with high letter frequency:

According to Mayzner \& Tresselt (1962a). there are three factors which are related to anagram solution times. These are: (1) anagram letter order, (2) word frequency (WF), and (3) transition probability. Transition probability is the probability or frequency with which given letters follow or proceed other letters. Total transition probability for the four letter-pairs of a five-letter anagram is obtained by adding the four transition probabilities; this sum is referred to as the anagram transition probability (ATP). Mayzner \& Tresselt (1959) have shown that the sum of the bigram frequencies associated with successive pairs of letters in the problem was related to the speed of anagram performance. As this value increases, so does the solution time.

Analogous to ATP but calculated in terms of the solution word, word transition probability (WTP) is also a factor known to influence anagram performance as can be seen in studies by Mayzner \& Tresselt $(1962 a, 1963)$. Words with high WTP were solved significantly faster than words with low WTP.

Word frequency (WF), is another effective variable in the solving of anagrams (Mayzner \& Tresselt. 1958).

Letter frequency (LF) is the total of single letter frequencies associated with anagram letters. In this study, the objective was to evaluate the effect of LF on the solution of anagram problems in the light of a control over WTP, ATP, and WF.

The specific hypothesis being investigated was that anagrams formed from words with low letter frequency (LLF) would be solved in a shorter amount of time, and more often, than anagrams formed from words with high letter frequency (HLF) witl WTP, ATP, and WF controlled.
Subjects. The 15 naive female Ss were undergraduate students at the Pennsylvania State University.

Stimulus Material. The problems consisted of 16 five-letter anagrams typed in capitals ( $3 / 8$ in. in height) and centered on plain white $81 / 2 \times 51 / 2$ in. cards. All words were selected from the Thorndike \& Lorge (1944) AA and A categories thus controlling word frequency. According to single letter counts prepared by Underwood \& Scliulz (1960, p. 69), half of the words had LLF totals $(M=15,082$, range $11,613-16.815)$, while the remainder were HLF (M $=23,729$. range $19,784-27,671)$. Word transition probability (WTP) was approximately equal for the two groups of words. Calculations based on bigram frequencies tabulated by Mayzner \& Tresselt (1962b) yie!ded means of 167 for the LLF words and 174 for the HLF words, thus favoring the HLF words. Anagram transition probability (ATP) was also approximately equal for the two groups. These calculations were based on bigram frequencies tabulated by Underwood \& Schulz (1960, p. 333); ${ }^{2}$ means being 691 for LLF and 688 for the HLF groups, and again favoring the HLF words. The anagram letter orders (LO) were all reasonably dissimilar to those of the unique solution words. As can be seen from calculations of the Kendall tau coefficient between anagram and unique solution words, see Table 1, the HLF group had more extreme tau values. It is reasoned that anagrams either sinilar to solution order or its direct reversal would enhance the solution of the anagram formed from this group. Thus here, too, the control favored the HLF words where exact equivalence could not be achieved.

To summarize the method, 16 anagrams were devised from 16 words classified as AA or A by Thorndike and Lorge. The WTP, ATP. WF, and LO were controlled between the two groups of words. Hulf of these words were of low letter frequency, the remainder were of high letter frequency.

Procedure. All Ss were tested individually. Each S attempted to solve 16 five-letter anagrams presented one at a time. Each anagram was set into a cardboard holder so that it was perpendicular to the table and the method of presentation was the same for each anagram so as not to affect S's view of problem. The anagrams were presented in ordered pairs: half of the Ss started the task with the LLF member of the pair, and the other Ss began with the HLF member of the pair. The pairs of anagrans were presented in the same order throughout the experiment (see Table 2 for order used). Instructions given orally indicated that each anagram had a unique solution which was a common English word but not a proper name. For each problem, a maxinum of $2 \mathrm{~min}$ was allowed for solution. Two practice anagrains (BUILT. LBTUI and STAND. DTNSA) were presented prior to the experiment proper.

Table 2

Summary of Experimental Problems and Solutions, Solution Times (in sec), and Number of Solutions

\begin{tabular}{|c|c|c|c|c|c|c|c|c|c|}
\hline & $\begin{array}{c}\text { Pair } \\
\text { Nưnber }\end{array}$ & Word & WF & WTP & LF & Anagram & ATP & $\begin{array}{c}\text { Median } \\
\text { Time }\end{array}$ & $\begin{array}{l}\text { Number of } \\
\text { Solutions }\end{array}$ \\
\hline \multirow[t]{9}{*}{ Low } & 1 & BLACK & AA & 162 & 11,613 & BAKLC & 941 & 15.6 & 12 \\
\hline & 2 & CLAIM & $\mathbf{A A}$ & 141 & 16,815 & IMLCA & 1,555 & 99.4 & 8 \\
\hline & 3 & JUDGE & $\mathbf{A A}$ & 49 & 14,866 & UEGJD & 615 & 10.8 & 15 \\
\hline & 4 & LAUGH & AA & 57 & 15,292 & UHLGA & 433 & 57.0 & 10 \\
\hline & 5 & MUSIC & AA & 45 & 15,300 & IUCMS & 265 & 18.1 & 14 \\
\hline & 6 & MAJOR & A & 81 & 16,486 & AOMRJ & 752 & 10.9 & 11 \\
\hline & 7 & YOUNG & AA & 453 & 14,651 & OGNYU & 349 & 10.4 & 13 \\
\hline & 8 & BOUND & $\mathbf{A}$ & 340 & 15,633 & UDNBO & 615 & 8.2 & 12 \\
\hline & & Means & & 166.75 & 15.082 & & 690.63 & 29.55 & 11.87 \\
\hline \multirow[t]{9}{*}{ High } & 1 & HEARD & $\mathbf{A A}$ & 283 & 24,459 & RHDAE & 359 & 95.0 & 9 \\
\hline & 2 & THOSE & $\mathbf{A A}$ & 576 & 27.671 & OEHTS & 985 & 120.0 & 7 \\
\hline & 3 & AWAKE & $\mathrm{A}$ & 25 & 21.237 & WKAAE & 64 & 0.0 & 15 \\
\hline & 4 & ENJOY & AA & 32 & 19,784 & OYNJE & 222 & 100.6 & 8 \\
\hline & 5 & KNIFE & $A$ & 17 & 20,332 & EFNKI & 551 & 7.0 & 14 \\
\hline & 6 & HOTEL & A & 184 & 25,854 & OLIILT & 305 & 120,0 & 2 \\
\hline & 7 & WRITE & AA & 146 & 25,103 & RTWIE & 1.760 & 8.4 & 1.3 \\
\hline & 8 & SPITE & A & 128 & 25,394 & EIPTS & 1.256 & 79.5 & 9 \\
\hline & & Means & & 173.86 & 23.729 & & $6 \times 7.75$ & 67.06 & 9.02 \\
\hline
\end{tabular}


Table 1

Frequency of Results of Kendall Tau Coefficient for Letter Order Difference Between Anagram and

Unique Solution Word

\begin{tabular}{ccc}
$\mathrm{T}$ & LLF & HLF \\
\hline .40 & 1 & 2 \\
.20 & 1 & 1 \\
.00 & 0 & 0 \\
-.20 & 4 & 2 \\
-.40 & 2 & 0 \\
-.60 & 0 & 3 \\
\hline
\end{tabular}

Responses were given orally, and Ss were not permitted to use paper and pencil; the correct solution word was given to the Ss before going on to the next anagram. Solution periods were measured in tenths of a second with the use of a stopwatch.

Results. The total solution times for the HLF and LLF lists were significantly different $(t=3.095, \mathrm{df}=14, .005>\mathrm{p}>.001$, one tail), and supported the hypothesis. The number of HLF and LLF words recognized was also significantly different $(t=3.076$, $\mathrm{df}=14, .005>\mathrm{p}>.001$, one tail), and supported the hypothesis. The data for individual words are presented in Table 2.

Discussion. The results indicate that angrams of low letter frequency are solved faster and more frequently than anagrams of high letter frequency. It is reasoned that uncommon letters, if present, reduced the number of letter groupings which were plausible. In a sense, they remove more uncertainty than common letters, and therefore provide greater information to the problem solver. According to Underwood \& Schulz (1960, p.76) the six least frequent or uncommon letters are "V, K, J, X, Z, and Q." Words which contained the letters " $\mathrm{K}$ " and " $\mathrm{J}$ " of this set were on the whole recognized faster than words which contained none of these letters. This can be seen in the comparison of the performance for the following words with the performance for the remainder of the list: (1) BLACK, (2) JUDGE, (3) MAJOR, (4) AWAKE, (5) ENJOY and (6) KNIFE (see Table 2). The median solution times for these words and the remainder of the list were significantly different $(t=5.103, \mathrm{df}=14, \mathrm{p}<.001$, one tail). The comparison between the proportion of words correct in this list and the remainder of the words was significantly different $(t=5.085, \mathrm{df}=14, \mathrm{p}<.001$, one tail). These uncommon letters, since they required less time for examination, decreased the solution time from that of problems containing only high letter frequency letters. In this comparison medians were employed because of the artificial ceiling imposed by the $120 \mathrm{sec}$ time limit per anagram.

It should be noted that within each of the groups of items there was a high degree of variability in ATP, WTP, WF, LF, and LO. It appears to the author that the magnitude of the effect of LF interacts with the levels of the other variables, though the present experiment does not permit an evaluation of these interactions. Interaction between and among the controlled variables may have caused unsuspected relationships to emerge. Dominowski \& Duncan (1964) reported such an interaction between WTP and ATP. In order to investigate these interactions more homogeneous groups of solution words and anagrams at various levels of these control variables must be used.

From the conditions of this experiment, the conclusion can be drawn that the total letter frequency of a word influences the speed and frequency of anagram solution, with the low letter frequency increasing both the speed and number of anagram solutions. The generalization value of these results are limited by the small sample of words and only a single letter order for each anagram. These conditions should be kept in mind for future research.

\section{REFERENCES}

MAYZNER, M. S., \& TRESSELT, M. E. Anagram solution times: a function of letter order and word frequency. J. exp. Psychol., 1958, 56, 376-379.

MAYZNER, M. S., \& TRESSELT, M. E. Anagram solution times: a function of transition probabilities. J. Psychol., 1959, 47, 117-125.

MAYZNER, M. S., \& TRESSELT, M. E. Anagram solution times: a function of word transition probabilities. J. exp. Psychol, 1962a, 63, 510-513.

MAYZNER, M. S., \& TRESSELT, M. E. Tables of diagram and single letter frequency counts by word length and letter position for a sample of 20,000 words. Mimeographed copy, $1962 b$.

MAYZNER, M. S., \& TRESSELT, M. E. Anagram solution times: a function of word length and letter position variables. J. Psychol., 1963, 55, $469-475$.

THORNDIKE, E. L., \& LORGE, P. The teacher's word book of 30,000 words. New York: Columbia University, 1944.

UNDERWOOD, B. J., \& SCHULZ, R. W. Meaningfulness and verbal learning. Philadelphia: Lippincott, 1960.

$$
\text { NOTES }
$$

1. The counsel of Robert Seibel is gratefully acknowledged.

2. Mayzner and Tresselt's table are inappropriate for anagrams because the frequencies are for word length and bigram position in the word. 